\title{
ILUSTRACIÓN, DISEÑO Y PATRIMONIO ALIMENTARIO
}

\author{
María Fragoso Mora \\ Universitat Politècnica de València.maframo@posgrado.upv.es
}

\begin{abstract}
Although the birth and recognition of the graphic illustration discipline can be considered recent, in an art as vast as this there are no limits to represent different objects that have their charm in a sense other than the meaning of sight. This is due to the fact that in the world of the illustration, communication and symbolic representation are prioritized in an aesthetic, adapted and exemplary support that can play in tune with a popularization content. For such a complex sense of representing taste, that is, the recreation of the palate and flavor, the illustration has been endowed with a lot of technique to represent eating rituals, food and gastronomy. These techniques can be the selection of complementary colors, the handling of textures, the elaboration of the drawing, the graphic synthesis, among others. In this study, the relationship that the illustration has had in the food sector is developed and different cases will be analyzed to elaborate the reflection. These cases reflect different manifestations of illustration of design in different cultures: the cinematographic animations of Studio Ghibli in Japan, the iconography and archetype of Mexican food in franchises and the emerging illustrators from different countries that generate current food identities.
\end{abstract}

Keywords: illustration, food heritage, food, design, graphic design, studio ghibli, mexican food, illustrators.

Resumen: Aunque el nacimiento y reconocimiento de la disciplina de la llustración puede considerarse reciente, en un arte tan vasto como este no existe límites para representar distintos objetos que tengan su encanto en un sentido diferente al visual. Esto se debe a que en el mundo de la llustración se prioriza la comunicación y representación simbólica en un soporte estético, adaptado y ejemplificador, que pueda jugar en sintonía con un contenido de divulgación. Para un sentido tan complejo de representar como lo es el gusto, es decir, la recreación del paladar y el sabor, la llustración se ha dotado de mucha técnica para representar ritos alimentarios, comida y gastronomía. Estás técnicas pueden ser la selección de colores complementarios, el manejo de texturas, la elaboración del dibujo, la síntesis gráfica, entre otras. En el presente estudio se desarrolla la relación que ha tenido la llustración en el sector de la alimentación y se analizarán distintos casos para elaborar la reflexión. Estos casos reflejan distintas manifestaciones de la llustración del diseño en diferentes culturas: las animaciones cinematográficas de Estudio Ghibli en Japón, la iconografía y arquetipo de la comida mexicana en franquicias y los ilustradores emergentes de distintos países que generan identidades alimentarias actuales.

Palabras clave: ilustración, patrimonio alimentario, alimentación, diseño, diseño gráfico, estudio ghibli, comida mexicana, ilustradores.

Citar como: Fragoso Mora, M. (2022). "Ilustración, diseño y patrimonio alimentario". En: Actas del III Congreso Internacional sobre Patrimonio Alimentario y Museos. 25-26 noviembre, 2021, Valencia, España. pp. 119-128. https://doi.org/10.4995/EGEM2021.2021.13286 


\section{Introducción}

Los límites de la representación gráfica se expanden más allá de los sentidos. Prueba de esto es que hoy en día convergemos entre miles de medios y expresiones estéticas que se adaptan a diferentes sectores, las bellas artes para la economía, la espiritualidad para el comercio, y muchas otras combinaciones más. También es el caso de la expresión gráfica de la "ilustración". Aunque el nacimiento y reconocimiento de la disciplina de la ilustración puede considerarse reciente, en un arte tan vasto como este no existe límites para representar distintos objetos que tengan su encanto en un sentido diferente al sentido de la vista. Esto se debe a que en el mundo de la ilustración se prioriza la comunicación y representación simbólica en un soporte estético, adaptado y ejemplificador, que pueda jugar en sintonía con un contenido de divulgación. Para un sentido tan complejo de representar como lo es el gusto, es decir, la recreación del paladar y el sabor, la ilustración se ha dotado de mucha técnica para representar ritos alimentarios, comida y gastronomía. Estas técnicas pueden ser la selección de colores complementarios, el manejo de texturas, la elaboración del dibujo, la síntesis gráfica, entre otras.

En el presente estudio se desarrolla la relación que ha tenido la ilustración en el sector de la alimentación y se analizan distintos casos para elaborar la reflexión. En un primer momento, se recapitula cómo se ha desarrollado la relación de expresiones gráficas (como la pintura, el dibujo y más tarde la ilustración) con la comida y la alimentación a lo largo de la historia. En un segundo momento, se habla de las características que visten a la ilustración del patrimonio alimentario. Y en un tercer momento, daremos pasos a casos de estudio que ejemplificarán distintas manifestaciones de la ilustración y del diseño en diferentes culturas: las animaciones cinematográficas de Estudio Ghibli en Japón, la iconografía y arquetipo de la comida mexicana en franquicias y los ilustradores emergentes de distintos países que generan identidades alimentarias actuales.

\section{Objetivos}

Los objetivos que se persiguen con este estudio son los siguientes:

- Comprender la evolución histórica de la disciplina de la ilustración como testimonio de ritos y tradiciones alimentarias.

- Identificar las características de la ilustración de la comida y la alimentación como propiedades logradas y distintivas en los medios de expresión gráficos.

- Esbozar el papel de la ilustración de la alimentación en diferentes medios de arte visual, como lo son los audiovisuales, el diseño y el sector comercial.

- Exponer 3 casos de estudio en diferentes culturas y geografías para ser una muestra representativa de las técnicas de la ilustración en el patrimonio alimentario.

\section{Desarrollo de la innovación}

\subsection{El posicionamiento de la ilustración actual}

No es un asombro reconocer que la representación gráfica de la vida y las cosas se vea explícito en la historia. A lo largo de los años, un sinfín de personas con manos hábiles se dedicaron a documentar la experiencia tangible e intelectual a través de formas y manchas. En el devenir del 
ser humano se encuentran múltiples muestras de esta intención gráfica desde antes de la formalidad histórica que supone la escritura. Porque antes de una intención codificada y alfabética, hubo una expresión sutil y sencilla pero completamente dotada de semántica, con esto se hace referencia a la expresión del dibujo, e incluso la pintura, mucho antes de su conceptualización. Las pinturas rupestres son el ejemplo más claro de dicha expresión, dónde el objetivo de su creación no era mucho menos estético, sino mucha veces meramente comunicativo y posiblemente espiritual.

La evolución de la expresión de lo gráfico ha tenido diversas variantes. Jaques Aumont (1992) en su obra La imagen, menciona que la construcción de imágenes gráficas crea relaciones con el espectador que las observa, esto gracias a los valores representativos o simbólicos que "entregan mensajes de acuerdo con la intención del autor y, utilizadas en contextos socioculturales específicos, pueden influir en la forma de pensar de las personas" (Menza, 2016, p. 267). Esta forma de comunicación se fue consolidando como una bella arte por medio del concepto de pintura, (posteriormente se reconocido el dibujo) y hasta su innegable implicación con el ejercicio de la arquitectura y las matemáticas. Sin embargo, el gran concepto que nos atañe en la presente investigación es ejercicio de la ilustración, una variante que sale de las artes plásticas y del diseño gráfico como la expresión más contemporánea de la expresión gráfica histórica.

Se puede considerar que la disciplina de la ilustración nace formalmente en el siglo XIX, al tiempo que nacen los primeros esbozos del diseño gráfico y la tendencia de las "arts \& crafts". Sin embargo, no hay que olvidar que ya en la Edad Media, cuando los copistas de los monasterios reescribían los inicios de libros, se tomaban la tarea de adornar y decorar dichos manuscritos con imágenes alusivas y llamativas, siempre a mano. Por algo se llamaban los manuscritos "miniados" por las miniaturas.

La ilustración tiene una antigüedad considerable en acción. Ha estado presente especialmente en el sector de los libros y, si acaso, podríamos mencionar que nace directamente del ejercicio editorial. Porque la ilustración nace para "iluminar", "dar luz", a la información escrita, se consolida como recurso necesario ante una masa poblacional que solía ser analfabeta, como lo fueron por mucho tiempo las pinturas eclesiásticas del románico del maestro de Tahull, los vitrales góticos de Notre Dame de París o los murales gigantes de Diego Rivera y Siqueiros.

Se considera que la ilustración "ha tenido gran importancia como un recurso de comunicación visual, y ha favorecido la comprensión de textos y transmisión de mensajes en ámbitos educativos, científicos y culturales, a través de medios como carteles, libros narrativos, educativos o científicos" (Menza, 2016, p. 267). Laura Varsky define a la ilustración como "un dispositivo comunicativo". Donde su actuación principal es "la construcción de discurso a partir de la imagen. Y en esa construcción se pone en juego la voz de quien ilustra. Su manera de ver al mundo, de interpretarlo y transmitirlo." Esta definición es un conjunto fresco y flexible que responde a la expresión de la ilustración hoy en día. Porque ya está creada para dar soporte y complemento a un texto escrito, sino para tener una voz propia que no llega a ser un discurso firme y establecido como lo podría ser una pintura. Hoy en día, se reconoce que la ilustración es una disciplina que nace contemporáneamente y tiene cabida en espacios académicos.

Sin embargo, el símil interesante para hablar de los ancestros de la ilustración es justamente rememorar la consideración de las pinturas rupestres. El dibujo prehistórico estaba dotado de vida y movimiento porque se implicaban directamente en la vida de sus autores. Al contrario del 
bodegón, por ejemplo, también llamado "naturaleza muerta" que representa una estática inmovible, solemne, que enmarca un cuadro entorno a objetivos alimentarios.

La ilustración hoy en día se abre caminos mediante diferentes canales. Uno de ellos, tal vez el más mediático, es el de las Redes Sociales. A partir de que las plataformas como Facebook, especialmente Instagram y recientemente Tik Tok, se consolidan como escaparates para el contenido audiovisual la industria de los creadores de arte gráfico y visual tomaron la oportunidad para que su propio perfil se convirtiera en un portafolio y más allá: los contenidos digitales en las Redes Sociales se han convertido en una gran muestra de curaduría, al punto de que la "curación de contenidos" es un término oficial y potente para la comunicación y el marketing. Justamente, la ilustración contemporánea ha aprovechado la situación, muestra de ello es la inmensa cantidad de artistas, diseñadores e ilustradores que están expresamente declarados como tal en la información de su perfil personal.

La manifestación de la ilustración en Redes Sociales responde directamente a los movimientos y tendencias de diferentes industrias. Mientras que para el mundo editorial se complementa con la escritura, como es el caso del Álbum Ilustrado donde narrativa y grafica son inseparables, la ilustración se ha valido para involucrarse en el mundo audiovisual, especialmente en la innovación, pero también en el sector comercial. La ilustración ahora, además de ser una expresión artística por sí misma, se usa también para vender.

Existen variedad de ejemplos de ello: la industria de la moda tiene como tendencia la selección de ilustradores para confeccionar piezas de ropa y accesorios de colección, los objetos de papelería y de uso personal han seguido la misma tendencia, y más aún, los comercios del sector de la hostelería no se han quedado atrás. Mientras que en la inmaculada figura del pintor se buscaba conseguir una obra individual para colocarla en una entidad de prestigio, público o privado, ahora los encargados de hoteles, restaurantes o incluso las PYMES, buscan decorar sus infraestructuras con motivos ilustrados o para configurar toda su identidad y comunicación corporativa.

Las diferentes técnicas de ilustración en el siglo XXI son una muestra flexible y dinámica de cómo la representación gráfica puede establecer un diálogo más íntimo y cercano con sus espectadores. Muestra de ello se desarrollará al detallar cómo se ha relacionado la ilustración contemporánea con el patrimonio alimentario y cuáles son los grandes atinos que tiene como oportunidad de posicionamiento para la industria y la recreación del entretenimiento.

\subsection{Dibujos deliciosos}

La injerencia que ha tenido la ilustración en la industria de la alimentación es un fenómeno particular. Pues ha trazado su propio camino a través de las múltiples expresiones que demuestra la ilustración hoy en día.

Un concepto popular para definirnos a este tipo de patrimonio alimentario es llamado la "ilustración gastronómica" que está presente en los modos de preparar alimentos, como lo son las recetas y también en la industria de la hostelería. Este tipo de ilustración se reconoce principalmente en la industria editorial, tanto en libros como en revistas que tienen una sección especial dedicada a la alimentación y a la preparación de alimentos. Sin embargo, también el llamado packaging, que es la técnica de crear embalajes y envases para productos, se ha valido de la ilustración para mejorar la comercialización de los alimentos. Hoy en día, la ilustración de comida, 
alimentos y modos de cocinar está muy presente en la web 2.0, donde las redes sociales y las plataformas digitales necesidad indiscutiblemente de una curación de contenidos multimedia. La ilustración, como se ha dicho anteriormente, ha tenido un papel cumbre para esta creación de contenidos, y el sector de la alimentación no se queda atrás.

Como se ha dicho, se pensaría que el bodegón sería el antecedente directo de la ilustración de alimentos y comida, sin embargo, se encuentra más similitud en la representación del rito alimentario expresado en las pinturas rupestres. La historia de la "ilustración gastronómica" o también Ilamada "Food Illustration" como concepto definitorio en inglés, se remite a los orígenes del diseño como herramienta de comercialización, desde los carteles hechos a mano que señalaban cafeterías y restaurantes, hasta los grandes anuncios espectaculares de gran tamaño que comenzaron a valerse del diseño gráfico para invitar a la audiencia al consumo.

Dentro de este tipo de ilustración, se puede encontrar la representación de las características propias del gusto ¿cómo se logra esta complementariedad? A continuación, presentamos aquellas características propias del arte plástico de la ilustración que permite esbozar los atributos del la comida y los alimentos:

- En la ilustración se encuentra una delimitación de los detalles tangibles de los alimentos, especialmente la capacidad de transmitir texturas, temperatura y densidad.

- La propuesta de colores y su alteración, permite que colores brillantes y con gran saturación den la sensación de ser apetecibles. Atributos indispensables para enmarcar el sentido del gusto.

- Búsqueda de la sencillez, y así lograr la capacidad de esbozar los platos de manera simple, aunque contengan diferentes ingredientes.

Estos tres atributos han permitido que la ilustración pueda representar los atributos de la comida y la alimentación de forma atractiva. Sin embargo, no es hasta ver una serie de ejemplos visuales que se puede ejemplificar esta teoría. Por ello, a continuación, se presentan tres casos de estudio que ejemplificarán como la ilustración de comida y alimentos está tomando camino en los medios y también en la industria propia de la alimentación.

\subsection{Comida animada: el caso del Studio Ghibli de animación en Japón}

Studio Ghibli es un estudio japonés de animación audiovisual que fue fundado en 1985 por el director de cine Hayao Miyazaki. Tiene un 23 largometrajes y 10 cortometrajes en su historia y múltiples premios por la crítica especializada de todo el mundo. Ha realizado diversas películas que han sido galardonadas y posicionadas dentro de la cultura popular, como lo es El viaje de Chihiro (2001), Mi vecino Totoro (1988), El castillo ambulante (2004), entre otras.

Las películas de Studio Ghibli se caracterizan por la técnica de animación 2D por tener unos paisajes iluminados con un gran nivel de detalle y por desarrollar temáticas entorno a la infancia, la vida cotidiana, las tradiciones japonesas, las relaciones familiares, las situaciones de problemáticas sociales, entre otras. Al ser una técnica de animación plástica 2D, es a partir de ilustraciones donde se desarrolla el movimiento de sus elementos y la intencionalidad gráfica. Por ello, una de las características que se quiere destacar en esta investigación es la presencia de la ilustración de comida y alimentos que aparecen en la mayoría de las películas; los cuales 
han sido muy característicos porque muestran un nivel mayor de detalle que otros elementos de la película como los personajes o los edificios.

De hecho, el estudio fue consciente de esta característica, pues en 2017, el Studio Ghibli Museum anunció la exposición "Delicious! Animating Memorable Meals" para representar y hablar de la experiencia alimentaria de los filmes. En la página del museo, en la presentación de la exposición, se lee como el estudio ha reconocido la importancia de esta representación gráfica:

Los fanáticos pueden recordar impresiones profundas de comida y escenas de comida en las películas de Studio Ghibli. (...) Las escenas de comidas informales están impregnadas de una enorme importancia narrativa. (...) Lograr un efecto dramático y crear comidas deliciosas y personajes que las disfruten (sus expresiones y gestos) proviene del poder de los dibujos finamente detallados. Alimentos que aún están calientes, que se ven suaves y tiernos, con el maravilloso sabor que se muestra en los rostros de quienes los comen: estas escenas de comidas son atractivas y encantadoras. No se necesita diálogo para transmitir la delicia y la felicidad. (Ghibli Museum, 2017)

La influencia de la comida en las películas de Studio Ghibli ha tenido tanta influencia en su público, que hay numerosos ejemplos de iniciativas que tratan de recrearlas. Como es el caso de la chef EN93, quien en su cuenta oficial de Instagram

(@en93.kitchen) se ha dedicado a recrear los platillos de las escenas de Studio Ghibli y con un número de 160 mil seguidores, ha dado una tendencia para que otros miles de usuarios sigan los pasos de consumir los alimentos de estas películas. De hecho, recientemente en 2021 se publicó el libro Las recetas de las películas del Studio Ghibli por la editorial Col\&Col Ediciones.

En 2021, en su cuenta de Twitter, el cofundador de Studio Ghibli, Toshio Suzuki ofreció una sesión de preguntas y respuestas, y una de las inquietudes que persistía en el público era la pregunta por la realización de la comida en las películas de Estudio Ghibli. El público preguntaba cómo se conseguía esa apariencia an atractiva y ese nivel de detalle. A lo que el con fundador respondió: "La razón por la que la comida luce tan bien es porque toda esa comida ya había sido cocinada por Miyazaki", haciendo alusión a la búsqueda perfecta del detalle por la cual el estudio ha alcanzado fama internacional.

El caso de la ilustración en los alimentos de las películas de Studio Ghibli es uno de los ejemplos más representativos de la cultura popular para hablar de este sincretismo entre diferentes sentidos, como el sentido audiovisual puede compaginar perfectamente con el sentido del gusto exponiendo características que hacen de la expresión artística una experiencia sensorial.

Studio Ghibli y su bagaje tradicional propios de la cultura en la que se inserta reconocen la valía de reconocer el patrimonio alimentario a través de la ilustración animada:

Dibujar comida es dibujar cultura e historia, lo que requiere una variedad de conocimientos y curiosidad para crear imágenes cinematográficas ricas. (...) Esperamos sinceramente que llegue a comprender la profundidad y riqueza de las escenas de comida que están llenas de vida. (www.ghibli-museum.jp, 2017)

La aceptación de la animación 2D, la ilustración del tipo "cartoon" o "anime" con muestras ya reconocidas y analizadas en espacios académicos y ahora, con la mirada desde el patrimonio alimentario, son también testimonios para el análisis de su influencia en la sociedad.

\subsection{El arquetipo y el ícono: el caso del diseño en la comida mexicana}

En el año 2010, la gastronomía mexicana fue declarada Patrimonio Cultural Inmaterial de la Humanidad por la Organización de las Naciones Unidas para la Educación, la Ciencia y la Cultura 
(UNESCO). Con este anunció se reconocía que la cocina en México es elemento crucial de identidad nacional, debido a su historia, creatividad, diversidad y trascendencia. (Fernández, 2016).

La mediaticidad que tiene la comida mexicana en el mundo ha dado nacimiento a una variedad grande de proyectos que tratan de llevar esa experiencia alimentaria a todos lados. Con esto nos referimos a las franquicias y restaurantes colocados fuera de la República Mexicana con la intención de llevar una experiencia extranjera a las calles de otros países. Como ha sido el caso de Taco Bell, Chipotle Mexican Grill o Chili's. Cabe destacar que, aunque el mercado de las franquicias de comida mexicana es significativo para este caso de estudio, es cierto que hay una curiosa uniformidad en restaurantes emergentes en muchos países donde se copia el estilo de comida mexicana sin pertenecer a ninguna corporación.

La característica que nos importa ahora de estas franquicias emprendedoras es el uso de la ilustración y el diseño que ha consolidado su imagen corporativa y que ha llegado a influir en la propia imagen de los alimentos que ofrecen. El ejemplo más representativo es el de Taco Bell, quien le ha vendido al mundo una imagen tradicional errónea del famoso platillo del "Taco". O Chili's, donde le da prioridad de su menú es presentar una mezcla variada de comida aparentemente picante pero que dista mucho de pertenecer a la tradicional comida mexicana reconocida por la UNESCO.

Dentro de las tendencias del diseño para la industria de la comida preparada, se destaca el llamado Food design para referirse a una disciplina que aplica al hecho gastronómico estrategias y métodos propios del diseño. Que al mismo tiempo "se entiende como una representación anticipada del acto alimenticio, aunque el concepto abarca mucho más que la pura decoración culinaria: desde la producción hasta la presentación, comunicación, comercialización, consumo del alimento... y su relación con todos los agentes involucrados" (Scoolinary, 2021). Sin embargo, además de la técnica del emplatado, que consiste en presentar alimentos en platos con fotografías estéticamente atractivas, lo que han hecho las franquicias arquetípicas de comida mexicana es modelar la imagen global que se tiene de este tipo de comida.

Para el diseño gráfico es fundamental jugar con sus elementos, como el color, el tamaño, la composición "de tal manera que se busque un objetivo visual y que el receptor logre decodificar e identificar el propósito, siempre cuidando la estética y la realidad de la imagen fotográfica" a la que están sujetos (García et al, 2020, p. 122). Y uno de los objetivos buscados para la promoción de una tradición alimentaria, es que un gran número de personas puedan apreciarla y disfrutarla:

"la gastronomía mexicana traspasa fronteras de forma significativa, por su historia, diversidad de ingredientes, técnicas, por su sabor, color, textura, aroma y los aportes nutricionales, por lo que cada día existen más restaurantes de comida mexicana en otras fronteras con una gran connotación e impacto en la sociedad. (García et al, 2020, p. 131)

Sin embargo, lo que han hecho las franquicias de cómica mexicana, es elaborar un diseño dinámico, limpio y "caricaturesco" de las formas de expresión de estos alimentos. Muchas veces manipulando su verdadera composición con tal de verse "atractivos" y casi "plastificados". Esto podría no verse exclusivamente en la comida mexicana. En la gastronomía china o la tailandesa, la italiana, la española, la japonesa, entre muchas otras, hay diferentes muestras de cadenas de restaurantes que buscan la adaptación de sus alimentos para llevar a todo el mundo. Solo que esta adaptación ha sido un cambio de identidad, de imagen y de elaboración para la comida mexicana. 
Anthony Bourdain, chef estadounidense con reconocimiento internacional especializado en comida mexicana expresó que "encontraba muy injusto que nuestra comida estuviera aún estereotipada como fritanga barata, pues la comida mexicana va más allá de los tacos o los burritos" (TKM en García et al, 2020, p. 132). Afortunadamente, iniciativas como el Conservatorio de la Cultura Gastronómica Mexicana (órgano consultivo de la UNESCO) o al Fundación Herdez tienen diferentes esfuerzos para conservar y difundir la tradición alimentaria en México desde sus orígenes y construcción histórica.

La ilustración y el diseño gráfico aplicados a la alimentación tradicional de cada país es una responsabilidad mediática, pues muchas veces la configuración gráfica afectará directamente al modo de posicionar un alimento y de compartirlo con más personas.

\subsection{Chefs de tinta: el caso de la ilustración alimentaria actual}

Como bien se ha mencionado anteriormente, la ilustración de alimentos y comida es una tendencia que va en alza no solo por su atractivo estético, sino también para su funcionalidad en muchos productos culturales. Ejemplo de esto es la siguiente lista de artistas que han innovado dentro de la ilustración de comida y alimentos.

- Melanie Chadwick. Es una ilustradora británica especializada en comida y mapas, los resaltan por su particular manera de los colores, las líneas y de toda la narrativa que atraviesan. Ha colaborado con diversas empresas para ilustrar la imagen corporativa, como Cornish Seasalt, Foodmentary, Ferment Magazine, American Airlines y Virgin Atlantic, entre otros. Tiene un curso en la plataforma Domestika de cursos asincrónicos titulado "Recetas ilustradas: crea dibujos deliciosos".

- Marinie Ruiz de Cabañas. Es una ilustradora española-mexicana que se decida a la ilustración de alimentos y colabora con diversos periódicos y publicaciones periódicas como El País, Buen Vida, Sobremesa. En boca de la propia artista, ella menciona que este tipo de expresión gráfica implica "pintar lo que comemos, lo que nos gusta, pintar nuestras tradiciones y nuestra cultura culinaria”, Afirma que por eso "la ilustración gastronómica tiene muchas variantes en el mundo dependiendo del ilustrador, donde viva y qué tipo de comida es la que pinta" (Ruiz de Cabañas, Palmera Magazine, 2021).

- Pier Paolo Spinazze. Es un artista italiano que se ha dedicado al streetpainting y al grafiti. Su propuesta se destaca por elaborar grafiti de comida para omitir y borrar mensajes de odio, especialmente aquellos que hacen referencia al racismo y la xenofobia.

- Chow Hon Lam. Es un ilustrador de Malasia también conocido como Flying Mous, que se dedica especialmente a la ilustración de humor, que ha permeado en otros proyectos de ilustración en ropa y tiras cómicas. Tiene una serie de ilustraciones donde convierte a los alimentos en personificaciones humanas en diferentes situaciones irónicas.

- Gretchen Röehrs. Es una ilustradora y diseñadora de moda estadounidense que ha configurado una exposición de ilustración de ropa intervenida a con diferentes alimentos reales.

- Pablo Fernández Tejón. Es diseñador, ilustrador y fundador del estudio gráfico ovetense Pixelbox que dedica u proyecto al año a hacer la sinergia entre alimentación y arte. En 
2015 presentó un proyecto titulado "llustradores a la mesa" donde hizo una selección de ilustradores para plasmar ilustraciones en platos.

Todos estos ilustradores han buscado maneras de exponer en su narrativa gráfica a los alimentos, su preparación, sus texturas, sus ingredientes y su manera de degustarlos. Cabe destacar que la lista de ilustradores de alimentos, ilustradores gastronómicos o también llamados "food ilustrators" es amplia y vasta, y con la exposición de las redes digitales, el catalogo de artistas va en aumento, así como la motivación para incursionar con técnicas graficas.

\section{Conclusiones}

El patrimonio alimentario representado en la ilustración tiene sus orígenes en tiempos remotos, desde el primer momento en que el ser humano fue capaz de representar en su vida cotidiana de manera gráfica, mucho antes de que comenzara la escritura. La expresión de los alimentos en las artes plásticas es un lugar común, pues el rito alimentario es parte inherente a una cultura, una tradición, un saber de valores, una relación social y espiritual también. Y esto no solo se le atribuye a las artes plásticas, sino también a la literatura y a otras disciplinas. En el caso de la reciente consolidación de la ilustración como disciplina artística, su relación con los alimentos y la comida ha marcado tendencia en diferentes sectores, especialmente en el comercial y el de la hostelería, pues es gracias a la implementación del diseño e ilustración, marcas enteras, corporaciones alimentarias, franquicias de restaurantes logran abrirse camino en el mercado a satisfacción de los consumidores.

De igual manera, la ilustración ha logrado configurar y desarrollar diferentes identidades gastronómicas a lo largo del mundo, como es el caso de los dos primeros casos de estudio. Tanto la comida japonesa se ha reinventado en la cultura popular gracias a Studio Ghibli en Japón, tanto como la comida mexicana se ha resignificado a lo largo del mundo gracias a franquicias como Taco Bell. La ilustración no ha sido inocente al momento de incrustarse en el mundo del patrimonio alimentario. Pero es una incursión que nos ha llevado a conocer innumerables propuestas de artistas que quieren revalorizar la comida como un arte, una manera de relacionarnos y una manera de expresarnos.

\section{Bibliografía}

(2015). "Comida ilustrada: Gretchen Röehrs". Itfashion. Consultado en: https://www.itfashion.com/ cultura/ilustracion/comida-ilustrada-gretchen-roehrs/

(2017). "Delicious! Animating Memorable Meals". Ghibli Museum. Consultado en: https://www.ghiblimuseum.jp/en/exhibitions/013127/

Cisternino (2015) ."Pon una ilustración en tu plato” República. Consultado en: https://www.republica. com/pan-del-dia/2015/10/22/pon-una-ilustracion-en-tu-plato/

(2020). "Una japonesa convierte en realidad la deliciosa comida de las películas de Ghibli” La Vanguardia. Consultado en: https://www.lavanguardia.com/cribeo/estilo-de-vida/20200816/482808563272/ japonesa-convierte-realidad-deliciosa-comida-peliculas-studio-ghibli-hayao-miyazaki-instagram. html 
(2020). "La vida diaria de la comida y bebida en divertidas ilustraciones". Old Skulls. Consultado en: https://www.oldskull.net/design/la-vida-diaria-de-la-comida-y-bebida-en-divertidas-ilustraciones/

(2021). "Recetas ilustradas: crea dibujos deliciosos". Domestika. Consultado en: https://www. domestika.org/es/courses/2008-recetas-ilustradas-crea-dibujos-deliciosos

Fernández. (2016). "Cómo llegó la gastronomía mexicana a ser patrimonio de la humanidad". Forbes. Consultado en: https://www.forbes.com.mx/forbes-life/ gastronomia-mexicana-patrimonio-de-la-humanidad/

García Hernández, et al. (2020). "El alcance de la gastronomía mexicana en otras fronteras a través del diseño gráfico por el medio de la Web”. En: Arte y diseño: discursos de la identidad cultural en América Latina. Núm. 101. Buenos Aires. Consultado en: https://fido.palermo.edu/servicios_dyc/ publicacionesdc/cuadernos/detalle_articulo.php?id_libro=819\&id_articulo=16929

Ibarra. (2021) ."Toshio Suzuki explica el diseño de la comida de las obras de Studio Ghibli”. PlayerOne. Consultado en: https://www.playerone.vg/2021/04/05/toshio-suzuki-comida-studio-ghibli/

Menza Vados. (2016). "La ilustración: dilucidación y proceso creativo". KEPES Grupo de Estudio en Diseño Visual, 13. Núm 13, pp. 265-296. Consultado en: https://revistasojs.ucaldas.edu.co/index. $\mathrm{php} /$ kepes/article/view/2770

Padilla. (2021). "Tamales, sal y pan de muerto: Por qué los alimentos son fundamentales para el Día de Muertos". Los Ángeles Times. Consultado en: https://www.latimes.com/espanol/vida-y-estilo/ articulo/2021-11-01/alimentos-comidas-dia-de-muertos

Ruiz de Cabañas. (2021). "Ilustración Gastronómica: Marinie Ruiz-de-Cabañas es la Artista que Pinta Comida". Palmera Magazine. Consultado en: https://palmeramagazine.com/ ilustracion-gastronomica/

Scoolinary Blog. (2021). "La importancia del diseño gráfico en la decoración culinaria". Scoolinary. Consultado en: https://blog.scoolinary.com/la-importancia-del-diseno-grafico-en-la-decoracionculinaria/

Valdes. (2020). "Con increíbles ilustraciones de comida, joven borra grafitis llenos de odio". Menuacapulco. Consultado en: https://menuacapulco.com/2020/12/29/ con-increibles-ilustraciones-de-comida-joven-borra-grafitis-llenos-de-odio/ 